\title{
McTAGGART'S PARADOX AND SMITH'S TENSED THEORY OF TIME
}

\begin{abstract}
Since McTaggart first proposed his paradox asserting the unreality of time, numerous philosophers have attempted to defend the tensed theory of time against it. Certainly, one of the most highly developed and original is that put forth by Quentin Smith. Through discussing McTaggart's positive conception of time as well as his negative attack on its reality, I hope to clarify the dispute between those who believe in the existence of the transitory temporal properties of pastness, presentness and futurity, and those who deny their existence. We shall see that the debate centers around the ontological status of succession and the B-relations of earlier and later. I shall argue that Smith's tensed theory fails because he cannot account for the sense in which events have their tensed properties successively, and he cannot account for the direction of time.
\end{abstract}

McTaggart's Paradox has fascinated philosophers since it was originally presented. In his famous essay on 'The Unreality of Time', McTaggart argues that since the essence of time is temporal passage - the change events undergo when they move from the future through the present and into the past-and since temporal passage is contradictory, time is contradictory, and therefore unreal. ${ }^{1}$ There are two basic steps in his argument: (1) temporal passage is the essence of time and (2) temporal passage is contradictory. Nowadays, few, if any, philosophers accept McTaggart's argument, and their rejection of it is based upon a denial of one of the two basic steps. Detensers (like myself) deny (1) and accept (2), whereas tensers accept (1) and deny (2). Although I will have something to say about McTaggart's reasoning in support of step (1), the main concern of this paper will be step (2); the thesis that temporal passage is contradictory. There have been several recent versions of the tensed theory of time that have attempted to avoid McTaggart's conclusion, but the most sophisticated is that put forth by Quentin Smith. ${ }^{2}$ Thus, after explaining McTaggart's positive conception of time, and his argument for its unreality, I shall consider Smith's recent attempt to avoid McTaggart's conundrum and argue that it is inadequate.

Synthese 107: 205-221, 1996.

(C) 1996 Kluwer Academic Publishers. Printed in the Netherlands. 


\section{MctAGgART'S POSITIVE VIEW OF TIME}

Though it is debatable whether or not time involves change, it is surely not debatable that change involves time. For if we are to understand how a single thing can have incompatible properties, and thus satisfy one essential ingredient of change, we must in some way specify the different times at which it possesses those properties. What, then, is time? McTaggart's thesis is that we must understand time in terms of temporal passage, and we must understand temporal passage in terms of the property of presentness moving across an ordered but non-temporal $\mathrm{C}$-series.

To see what is involved in this point consider three different descriptions of the fact of change.

(1) The apple is green before it is red.

(2) The apple is green at $\mathrm{t} 1$ and red at $t 2$.

(3) The apple is now green and will be red.

For the purposes of distinguishing three different ontological assays of time we will distinguish the different states of affairs that (1), (2) and (3) describe. On the first analysis time is relational, that is, the only intrinsically temporal entities are the B-relations of simultaneity, earlier and later, and change is reflected in the apple's being green occurring before the apple is red. On the second alternative time is absolute. There are intrinsically temporal individuals called "moments"and change is reflected by the apple having different and incompatible properties at (or relative to) different moments of absolute time. On the third account, time is tensed, and change is reflected in the different non-relational temporal qualities of presentness, pastness and futurity that events in the A-series acquire and shed.

According to McTaggart, the ontologically most perspicuous description of time and change is reflected in statements such as (3), for apart from the A-series with its distinctions of past, present and future, (1) and (2) do not reflect the fact of genuine temporal change. As we shall see, however, his reasoning is not very convincing since it is based on the assumption that he is trying to prove, namely, that without the A-series all that really exists is a non-temporal C-series.

Consider his argument against the claim that the B-series, (containing facts of the sort reflected by (1)), does not adequately represent change. He reasons that time involves change and therefore if the B-series alone is to constitute time (as the detenser maintains) then it too must involve change. But, he continues, there is nothing in the B-series which changes. 
Since sentences which describe temporal relations between events are always true, it follows, according to McTaggart, that events in the B-series always exist and so do not change by coming into existence and going out of existence. Nor do events in the B-series change their relations to each other. Consequently, if the B-series is to be a time-series, then its terms (events) must exemplify the temporal characteristics of pastness, presentness, and futurity and change with respect to them as time passes. In other words, time (temporal relations) and change require an A-series and temporal becoming.

McTaggart states this conclusion in The Nature of Existence:

... the series of earlier and later is a time series. We cannot have time without change, and the only possible change is from future to present, and from present to past. Thus, until the terms are taken as passing from future to present, and from present to past, they cannot be taken as in time, or as earlier or later; and not only the conception of presentness, but those of pastness and futurity must be reached before the conceptions of earlier and later and not vice versa. (1927, p. 271)

Thus, the first and essential point concerning McTaggart's positive conception of time is that while both the A-series and the B-series are essential to our ordinary thought and experience of time, the A-series and temporal becoming is more fundamental to the real metaphysical nature of time since temporal or B-relations are dependent upon temporal becoming (or A-properties). To put the same point otherwise, on McTaggart's positive conception of time, B-relations are not there from the outset but are generated by the moving of the NOW along a non-temporal, but ordered C-series.

McTaggart believes that the above argument holds even if we enrich our ontology with temporal individuals or moments of absolute time, and describe the fact of change by sentences like (2). For even if the apple is green at it and red at $t 2$, there is still nothing about either of those facts that changes. As McTaggart puts it, 'it is always a fact about the poker [or apple] that it is cold at one point in time and hot at another' (1927, p. 27). Thus, if (2) is to reflect the fact of change, then something more is needed: the apple's being green and the apple's being red (as well as the times at which those events occur) must themselves change from being future to being present to being past.

McTaggart's argument against absolute and relational time can also be expressed by claiming that a series whose terms stand in unchanging relations, but do not have A-characteristics, is not a temporal series. For, if a series of terms do not have changing A-characteristics then they do not have a direction, and without a direction the series is indistinguishable from an unchanging spatial series. 
C. D. Broad once expressed the difference between time and space by saying that whereas a series of points in space have an intrinsic order, the peculiarity of a series of events in time is that it not only has an intrinsic order, but also an intrinsic sense or direction:

Three points on a line have an intrinsic order, i.e., $\mathrm{B}$ is between $\mathrm{A}$ and $\mathrm{C}$, or $\mathrm{C}$ is between $\mathrm{B}$ and $\mathrm{A}$, or $\mathrm{A}$ is between $\mathrm{C}$ and $\mathrm{B}$. This order is independent of any tacit reference to something traversing the line in a certain direction. By a difference in sense I mean the sort of difference which there is between say, ABC and CBA. Now points on a straight line do not have an intrinsic sense. (Broad 1959, p. 57)

The point Broad is getting at may be clarified by noting that the change of an apple from green to red is a change in a given or intrinsic direction because the apple is first green and then red, or synonymously, it is green before it is red from any point of view. In this respect time differs from space since a spatial series has a direction only in reference to something external to the series. Thus, in order to account for (temporal) change, that is, how one and the same thing can first have a property and then lose it, we must be able to account for the direction of time and the difference between the temporal change of the color of an apple and spatial "change" of, say, the color of a lawn from being green at one end and brown at the other.

McTaggart concurs that there must be something more to temporal change than an ordered series of qualitatively different terms. As he puts it:

More is wanted, however, for the genesis of a B-series and time than simply the C-series and the fact of change. For change must be in a particular direction. And the $\mathrm{C}$-series, while it determines the order, does not determine the direction. 1fthe $\mathrm{C}$-series runs $\mathrm{M}, \mathrm{N}, \mathrm{O}$, $\mathrm{P}$, then the B-series ... can run either $\mathrm{M}, \mathrm{N}, \mathrm{O}, \mathrm{P}$ (so that $\mathrm{M}$ is earliest and $\mathrm{P}$ latest) or else $\mathrm{P}, \mathrm{O}, \mathrm{N}, \mathrm{M}$ (so that Pis earliest and $\mathrm{M}$ latest). And there is nothing either in the C-series or in the fact of change to determine which it will be. (1934, pp. 116-117; emphasis added.)

Clearly, then, for McTaggart, something more is essential to time and change than the $\mathrm{C}$-series, but what more? Alternatively, how are we to account for the direction of time and its difference from space?

We should not be surprised to read that McTaggart's account of the direction of time and change depends upon the A-series:

We can now see that the A-series, together with the C-series, is sufficient to give us time. For in order to get change, and change in a given direction, it is sufficient that one position in the C-series should be Present, to the exclusion of all others, and that this characteristic of presentness should pass along the series in such a way that all positions on the one side of the Present have been present, and all positions on the other side of it will be present. ... $[\mathrm{N}] \mathrm{o}$ other elements are required to constitute a time-series except an A-series and a $\mathrm{C}$-series .... It is only when the A-series, which gives change and direction, is combined with the C-series, which gives permanence, that the B-series can arise. (1934, p. 118) 
This passage further supports my interpretation of McTaggart's positive views on time according to which a concept of time involving a temporal A-series and a non-temporal C-series is necessary and sufficient to account for the transitory and the relational aspects of our common notion of time. Thus, on McTaggart's positive tensed theory of time the fact of change and the direction of time can be accounted for without presupposing unanalyzable temporal relations. On his theory, temporal relations are not ultimate, but are analyzable in terms of the moving NOW.

There is much that is objectionable in McTaggart's positive conception of time and in his criticism of the view that time consists solely of Brelations. The weakness I want to focus on concerns an ambiguity in his conception and use of the $\mathrm{C}$-series. On the one hand, before McTaggart proves that time is unreal he introduces the $\mathrm{C}$-series as a permanent, nontemporal, ordered series of terms which, together with the A-series, is the ontological ground of the B-series. On the other hand, after he has allegedly disproved the reality of time McTaggart introduces the $\mathrm{C}$-series in order to explain how it is that we misperceive the B-series as a time series. This ambiguity presents a problem for McTaggart. The existence of the $\mathrm{C}$-series as an ordered, but non-temporal series whose terms are in oneone correspondence with the terms of the B-series, is a theoretical posit introduced to explain how it is that we seem to experience events in time as forming a B-series. Thus, his use of the C-series is justified only after he has disproved the reality of time. Yet his argument against the B-series as well as his positive conception of time assume that the existence of the $\mathrm{C}$-series is logically prior to that of the B-series (since they assume that a $\mathrm{B}$-series without an A-series is a space-like $\mathrm{C}$-series), and so they assume what needs to be proved.

The issue between the tenseless and the (predominant) tensed theory of time can now be put clearly into focus. McTaggart claims that if time is real - if there is genuine succession - then the ontological ground of that succession must be the non-relational temporal properties exemplified by events and moments of time, if there are moments of time. Detensers reject the moving NOW and the monadic property of presentness, but nevertheless maintain that genuine succession exists and that the B-series alone contains the fact of change. Russell (1915), Broad (1921), Shorter (1984), Oaklander (1984), Williams (1994) and others have maintained that temporal relations are primitive and unanalyzable relations, and the difference between spatial and temporal relations is an irreducible qualitative difference. From this perspective, it is a mistake to suppose that if time is the mere succession of events, then the change involved is exactly like the spatial "change" in the color of the lawn one observes as one walks 
from the front to the back. On this view, the relation that distinguishes temporal order is just different from any spatial relation in the same sense that red and green are just different. Other detensers such as Griinbaum (1973), Mellor (1981) and Le Poidevin (1991), have maintained that temporal relations are definable in terms of causal relations and the direction of time is grounded in the direction of causality. Whether temporal relations are definable or not, detensers have rejected the tensed theorist's claim that temporal relations are dependent upon either tensed properties, tensed facts, or the passage of time.

Having clarified McTaggart's positive conception of time we can turn to the second step in McTaggart's argument where he attempts to demonstrate that time is contradictory, and therefore unreal.

\section{MCTAGGART'S ARGUMENT FOR THE UNREALITY OF TIME}

The main argument by which McTaggart attempts to prove that time is unreal may be stated as follows:

(1) If the application of a concept to reality implies contradiction, then that concept cannot be true of reality.

(2) Time involves (stands or falls) with the A-series and temporal becoming; that is, if the A-series involves a contradiction then time involves a contradiction.

(3) The application ofthe A-series and temporal becoming to reality involves a contradiction.

(4) Therefore, neither the A-series nor temporal becoming can be true of reality; thus time is unreal.

In support of step (3) McTaggart argues simply that if events move through time from the future to the present to the past, (or if presentness moves across the $\mathrm{C}$-series) then every item in time must be past, present and future. However, past, present and future are incompatible properties. Thus, the existence of the moving NOW entails a contradiction-every event both is and is not past, present and future - and time is unreal.

McTaggart was aware that the contradiction appears to have an obvious resolution if we specify the various times or when events have incompatible temporal properties. He went on to argue, however, that the appeal to time, that is, succession, to avoid the original contradiction contained in temporal attributions involves either a vicious circle or a vicious infinite regress. Appealing to succession involves a vicious circle because 
it assumes the existence of time in order to account for the way in which moments are past, present, and future. Time then must be presupposed to account for the A-series. But we have already seen that the A-series has to be assumed in order to account for time. Accordingly, the A-series has to be presupposed in order to account for the A-series. And this is clearly a vicious circle. (McTaggart 1934, p. 118)

In short, in order to account for something having incompatible temporal properties the defender of passage must assume that the term in question has those properties in succession, but in order for a term to be first future, then present, and then past, we must assume that it has incompatible temporal properties. Thus, one cannot appeal to succession in order to explain how time and change are possible without falling into a vicious circle.

To develop this last point further, recall that an account of time must provide an account of say, an apple'sfirst being green and then being red, or synonymously, its being green before it is red. McTaggart's account of change involves the claim that every event in the apple's history changes with respect to the properties of pastness, presentness, and futurity. However, A-changes in events can account for time and avoid the incompatibilities problem only if events gain and lose A-properties successively. Unfortunately, given McTaggart's positive conception of time that can only mean that first the apple's being green is present and the apple's being red is future, and then the apple's being green is past and the apple's being red is present, or more simply, that the green apple is present before the red apple is present. As the italicized words indicate, however, time or more specifically, the temporal relation of earlier than, must be assumed in order to account for A-changes in events, that is, for events having incompatible A-characteristics. But as McTaggart says, "we have already seen that the A-series has to be assumed in order to account for time" (since the B-series is defined in terms of the application of the A-series to the C-series). In other words, given the existence of a contradiction in the original A-series, we cannot avoid it by appealing to the relation of succession because the A-series has to be assumed to account for the succession and therefore, since the A-series is involved in paradox, succession is too.

McTaggart's difficulty with temporal predication can be put differently, in which the fallacy will exhibit itself as a vicious infinite regress rather than as a vicious circle. If we avoid the contradiction by claiming that $\mathrm{E}$ is future at $\mathrm{t} 1$, present at $t z$ and past at $t 3$, then $\mathrm{t} 1, t z$ and $t 3$ must refer to different moments of time. For if the events do not have their A-characteristics at different times, then they are either timelessly or simultaneously past, present and future and a contradiction ensues. What, then, is the basis of $\mathrm{t} 1$ being earlier than $t z$, and $t z$ being earlier than t3? Given McTaggart's analysis it can only be that Presentness moves along the series of moments in such a way that each moment is past, present and future. But then, the 
contradiction in the (first) level of events arises again at the (second) level of moments at which the preceding level can have its temporal properties. For this new series is genuinely temporal only if its terms occur in a given direction, but the direction of a series is generated by temporal attributions which has not yet been freed from contradiction. Thus, McTaggart concludes, whether we stop at a contradiction, or at the denial of genuine (A-series) change, time is unreal.

There is another way to understand McTaggart's argument. McTaggart claims that in order to distinguish a temporal from a spatial series one must ground the direction of time. In order to give time a direction, however, the different terms must have one and only one non-relational temporal characteristic. For if $a$ is past, $b$ is present and cis future, then we can read off the change in the direction of $a$ is earlier than $\mathrm{c}$, rather than $c$ is earlier than $a$. However, unless $a, b$ and $c$ change their temporal characteristics there is no genuine change. Hence, each of the terms must have the other two temporal characteristics as well, but then we can no longer determine the direction of the change, whether from $a$ to cor c to $a$.

Critics of McTaggart, such as Broad (1938), Levison (1987), Lowe (1987a), Prior (1967, 1968), Smith (1993) and others have been quick to point out that since there is no contradiction to be avoided in the first place, as no event ever is (nonsuccessively) past, present, and future (or present and not present), there is no need to set off on an infinite regress in order to avoid it. As Broad puts it:

I cannot myself see that there is any contradiction to be avoided. When it is said that pastness, presentness, and futurity are incompatible predicates, this is true only in the sense that no one term could have two of them simultaneously or timelessly. Now no term ever appears to have any of them simultaneously. What appears to be the case is that certain terms have them successively. Thus, there is nothing in the temporal appearance to suggest that there is a contradiction to be avoided. (Broad 1938, p. 313)

Of course whether that response is adequate depends on how one unpacks the notion of succession. According to tensers, if we take tense seriously, then $\mathrm{E}$ is past, present and future is never true. What is true is that

E is present, was future and will be past, orE is past, and was present and (still earlier) was past orE is future, will be present and will be (still later) past.

The dominant issue surrounding recent discussions ofMcTaggart's paradox is whether the appeal to tense can be given an interpretation that will resolve the difficulties with temporal passage.

According to defenders of the tenseless theory of time, none of the solutions to McTaggart's paradox and related problems are successful, and so they conclude we must give up the idea that events form a real A-series and change with respect to their temporal location in it. For detensers, 
'past', 'present' and 'future' are indexical expressions whose referent cannot be separated from the time of utterance, or from the utterance itself. Thus, for example, on the token-reflexive account that Mellor propounds, the temporal relation between the date at which one says, thinks, or writes down a tensed sentence and the event or thing that it is about provides an objective basis for the truth value of any tensed sentence. A present tense sentence token is true if and only if it occurs (exists tenselessly) at (roughly) the same time as the event it is about; a past tense token is true if and only if it occurs at a time later than the event it refers to, and so on (Mellor 1981, 5-7). Thus, on the token-reflexive account, the facts in virtue of which tensed sentence tokens are true are tenseless. Tensers, however, cannot accept this way out of McTaggart's paradox since to do so is to leave out something essential to time, namely, temporal passage. They are obliged, therefore, to make sense of the tensed theory of time while also avoiding McTaggart's paradox. In what follows I shall critically discuss Quentin Smith's recent attempt to accomplish that task.

\section{SMITH'S RESPONSETO MCTAGGART'S PARADOX}

In his recent writings Quentin Smith has argued that "the idea that presentness, pastness and futurity are properties does indeed entail an infinite regress, but that this regress is neither vicious nor constituted of tenseless [or simultaneous] predications". (Smith 1994a, p. 180; cf. 1994b, 1993.) In the remainder of this paper I want to explain why I do not believe that Smith's interpretation of the tenses succeeds in avoiding the vicious infinite regress of temporal attributions that McTaggart claimed to uncover in his paradox.

Let us begin with the three statements: " $\mathrm{E}$ is now present", and " $\mathrm{E}$ is now past", and "E is now future". These are mutually contradictory unless it is specified that E has these incompatible properties successively. "In tensed language", Smith writes, "this means that the event is present, will be past and has been future or that it is past, and has been future and present, or that it is future and will be present and past" (1994a, p. 181). According to Smith, the reality of temporal attributes as reflected in his analysis of the tenses implies an infinite regress of inherences of presentness inhering in their own inherences. That is, the correct analysis of "E is present" is "E is present, and the being present of $\mathrm{E}$ is present, and the being present of the being present ofE is present, and so on infinitely" (1994a, p. 185). He explains this by saying that

the first conjunct predicates presentness of the event $\mathrm{E}$ and each of the remaining conjuncts predicates presentness of a different inherence of presentness; the second conjunct 
predicates presentness of the inherence! of presentness in E, the third conjunct predicates presentness of the inherence 2 of presentness in its inherence in E, and so on. (1994a, p. 187)

This passage makes it clear that for Smith, inherence exemplifies the temporal attribute of presentness.

Similarly, the correct analysis of "E is past" and "E is future" involves the inherence of presentness in an infinite number of inherence relations. Thus, Smith says, "[T]he correct explication of"E is past" is $\mathrm{E}$ is past, and the being past of $\mathrm{E}$ is present, and the being present of the being past of $\mathrm{E}$ is present, and so on infinitely. An analogous complete explication is given to "E is future" (Smith 1994a, p. 187).

In an earlier paper I argued that Smith's account of the tenses does not escape McTaggart's paradox since to avoid an event's having incompatible A-properties simultaneously he is forced to maintain that inherence relations have incompatible A-properties simultaneously (1987). Smith objected that my argument assumes that events or inherence relations have their tensed properties nonsuccessively. He continues,

But Oaklander gives no justification for this assumption. Like McTaggart he simply asserts that whatever possesses the three temporal properties must possess them simultaneously. By importing this unjustified and foreign assumption into the tensed theory of time, Oaklander, like McTaggart, proceeds to deduce the incoherence of the tensed theory. But this assumption is not a part of the tensers theory of time. According to this theory, something [e.g., an event or an inherence relation] possesses the three incompatible properties only successively. (Smith, 1993, 174)

In what follows I shall argue that Smith cannot account for an event or an inherence relation having incompatible properties successively and so cannot avoid a McTaggartian-type critique of his tensed theory of time.

To see what is involved, recall that Smith attempts to remove the appearance of a contradiction in the statement " $E$ is past, present and future" by interpreting it to mean that

(1) E is present, will be past and has been future or

$\mathrm{E}$ is past, and has been future and present, or

$\mathrm{E}$ is future and will be present and past.

But this move does not avoid a contradiction. For consider the second disjunct in (1), namely,

(2) E is past, and has been future and present. 
The second and third conjuncts in (2) still harbor a contradiction. For the attribution of futurity and presentness toE in the past is just as contradictory as their attribution to $\mathrm{E}$ in the present, unless it is specified that $\mathrm{E}$ has them successively (or at different times) in the past. However, Smith cannot account for $\mathrm{E}$ having had the properties of futurity and presentness in succession. For, on his analysis, ifE has been future, then futurity inheresl in $\mathrm{E}$ and pastness now inheresz in the inherencel of futurity in $\mathrm{E}$. And if $\mathrm{E}$ has been present, then presentness inheresl in $\mathrm{E}$, and pastness now inheresz in the inherencel of presentness in E. There is, however, nothing in either of these two tensed facts that provides a ground for futurity having inhered1 in E earlier than presentness inhered1 in E, and thus there is nothing to account forE's having had the properties of futurity and presentness successively. Yet, without such an account the attribution of presentness and futurity to $\mathrm{E}$ in the past is contradictory.

A similar difficulty arises regarding the third disjunct in (1):

(3) E is future, and will be present and past

since it too contains a contradiction unless it is specified that $\mathrm{E}$ will be past after $\mathrm{E}$ will be present. But on Smith's theory, there is no basis for $\mathrm{E}$ being first present and then past in the future. For, if $\mathrm{E}$ will be present, then presentness inheres1 in $\mathrm{E}$, and futurity now inheresz in the inherence of presentness in E, and ifE will be past, then pastness inheres! in E, and futurity now inheresz in the inherence! of presentness in E. Unfortunately, nothing in either of those two tensed facts entail that $\mathrm{E}$ will exemplify pastness after it exemplifies presentness, and without a ground for succession, the contradiction involved in presentness and pastness inhering in $\mathrm{E}$ (in the future) remains.

Smith cannot avoid these arguments by distinguishing different degrees of pastness or futurity, e.g., being past by two hours or being future by two hours. For ifE was future earlier thanE was present, then on Smith's analysis that would imply that, say, being past by two hours presently inheres 2 in the inherence! of futurity in $\mathrm{E}$ is earlier than being past by one hour presently inheres 2 in the inherencel of presentness in E. That, however, implies a contradiction, since Smith maintains both that "the Brelations of earlier and later obtain between two events only if at least one ofthe events is not present" (1993, 197; emphasis added), and that if"E was future earlier thanE was present", is true, then the B-relation of earlier than obtains between the present inherence of being past by 2 hours ... in $\mathrm{E}$, and the present inherence of the being past by 1 hour ... in E. In other words, on Smith's analysis the temporal relation of earlier than obtains between two events that are present and that is absurd. ${ }^{3}$ 
There remains the first disjunct in (1) namely,

E is now present, will be past, and was future.

In order to avoid McTaggart's paradox and account for an event having its A-properties successively, Smith must show that (4) is consistent, and adequately reflects the passage of time and the direction of change. In what follows, I will attempt to demonstrate that he is unable to do so.

Consider the sentence "Event E will be past". On Smith's analysis, this means that the inherence of pastness in $\mathrm{E}$ is such that futurity now inheres in it. To state the same analysis somewhat differently, E exemplifies1 pastness, and exemplification! exemplifies 2 futurity, and exemplification 2 exemplifies3 presentness. As Smith himself puts it:

If $\mathrm{E}$ is now present, then it will be past. This latter clause means that futurity inheres in the pastness of E. But when does futurity inhere in the pastness ofE? ... Futurity now inheres in the pastness of E.... In terms of property-inherences, this means that presentness inheres in the inherence of futurity in the inherence of pastness in E. (1993, p. 171; my emphasis in the last sentence.)

What I wish to argue is that on Smith's analysis of"E will be past" either a vicious infinite regress ensues since it implies a contradiction that cannot be resolved by appealing an infinite regress of inherence relations, or he cannot account for the direction oftime.

The crucial-and fatal-move in Smith's analysis is the claim that the inherencez of futurity in the inherencel of pastness in E, is present. For if the second order inherence, or exemplificationz, is now present, then it exists now. If, however, exemplificationz exists now, then the term, in this case exemplification!, that exemplifiesz futurity, must also exist now. (I am (for the moment) assuming that if an inherence or exemplification "relation" (of any level i) exists now, then there must also exist now a term that exemplifiesi a property.) Consequently, if the "tie" (exemplificationz) between exemplification! and futurity exists now, then it must be the case that exemplificationl exists now. However, if exemplificationl exists now, then it must be present. Since, by hypothesis, exemplification! is future, it follows that exemplification is both present and future, or does now exist and does not now exist, and that is a contradiction.

It is no use trying to avoid this contradiction by claiming that (a) exemplificationl is future and will be present, or (b) exemplification! is present and was future, or (c) exemplificationl is past and was present and (still earlier) future. In the first place, (a) contradicts the original assumption that $\mathrm{E}$ is now present, and (b) contradicts the assumption that $\mathrm{E}$ will be past. For if exemplification! is future, then it cannot exemplifyz 
presentness as it must if $\mathrm{E}$ is now present. On the other hand, if we suppose that exemplification $_{1}$ is now present, meaning that exemplification 1 exemplifiesz presentness, and exemplificationz exemplifies 3 presentness, then exemplification! cannot now exemplifyz the property of futurity and that contradicts the assumption that $\mathrm{E}$ will be past. Finally, (c) contradicts the assumption that $\mathrm{E}$ was future. For if exemplification 1 is past, then exemplification! exemplifiesz pastness and exemplificationz exemplifies 3 presentness. However, if exemplificationz exemplifies presentness then not only exemplification, but also exemplification 1, must exist now. That, however, contradicts the assumption that $\mathrm{E}$ was future, that exemplification 1 is past. For if exemplification! now exists then it must exemplifyz presentness.

Thus, Smith's account of tensed exemplification does not explain how an event (or the inherence of an A-property in an event) can have the properties of pastness, presentness, and futurity successively. However, if an event or inherence relation must have its monadic temporal properties nonsuccessively, then the contradiction and ensuing vicious infinite regress contains reasonable grounds for inferring, as McTaggart did, that A-properties do not exist.

Of course, it is open to Smith to reject what I have assumed to be a principle, namely, that only what exists now can now exemplify a property. In other words, he might claim that on the tensed theory it is a fundamental principle that an event or an inherence (or exemplification) relation can exemplify a temporal property at a time at which it does not exist. However, if Smith rejects the principle in question, then he is involved in another difficulty. For ifthe inherence! ofpastness in E does not exist when futurity inheres$_{2}$ in it, and $\mathrm{E}$ does not exist when it exemplifies 1 pastness, then how can pastness inhere in $\mathrm{E}$ ? The ontological ground ofpastness inhering in $\mathrm{E}$ would be the property of pastness, and the inherence 2 of futurity, but it is difficult to see how that could be the ground of the truth of"E will be past". How can it be true now that the pastness of $\mathrm{E}$ is future, if all that exists now is the property of pastness, and the exemplification of futurity? There is nothing (E) that exists that exemplifies pastness, and nothing now exists that exemplifies futurity. So, Smith's analysis is faced with a dilemma. If we accept the intuitively plausible principle that an entity (in particular the relation of inherence) can exemplify a property only if it exists, it follows that first order inherence relations have incompatible temporal properties nonsuccessively. On the other hand, if Smith rejects that principle then, when $\mathrm{E}$ will be past, neither E nor the inherence of pastness in E exist. Thus, the truth of "Event $\mathrm{E}$ will be past" does not have a sufficient ontological ground. 
The dilemma I just raised is closely connected with another. Recall, the passage of time, and its direction, is reflected in the notion that:

What is present was future and will be past.

This sentence implies that what was first future, became present and then became past, rather than the other way around. However, Smith's analysis of the states of affairs described by (5) E will be past, (6) E is now present and (7) E was future, is inadequate to account for the direction of time and change. For the ontological analysis of (5) does not contain $\mathrm{E}$ or the exemplification $_{1}$ of pastness by E, but only a second level exemplification relation and the properties of pastness and futurity. Analogously, (7) does not contain $\mathrm{E}$ or the exemplification! of futurity byE, but only a second level exemplification relation, and the properties of pastness and futurity. Thus, the facts that $\mathrm{E}$ will be past, and $\mathrm{E}$ was future contain the same constituents, namely, a second level inherence or exemplification relation and the properties of pastness and futurity. What, then, could be the ontological ground of the difference between (5) and (7) and the basis forE's being first future, then present and then past, orE's being future before being present or past? The direction of the change in E from future to present to past, rather than the other way around seems to be left unaccounted for. ${ }^{4}$

Thus, Smith is impaled on the horns of a dilemma. Either he accepts the intuitively plausible principle that an entity can now exemplify a property only if it exists now or he does not. If he accepts the principle, then a contradiction ensues since the same inherence relation has incompatible temporal characteristics nonsuccessively. On the other hand, if he denies the principle, his ontological assay of facts described by sentences like (5) and (7) fail to ground the direction of time and change. The only way he could do so would be by appealing to facts of the sort described by (6) E is now present. However, before such facts can provide an account of the direction of time, Smith would need to give a direction to the multitude of facts of that form. But if the argument of this section is sound, then Smith's analysis of the tenses will be insufficient to accomplish that task. Thus, in order to avoid McTaggart's paradox and provide a ground for the direction of time, Smith must countenance tenseless temporal relations between terms that exist and are located at some time $t$ without tensed properties. That is, he must abandon the tensed theory of time.

\section{CONCLUSION}

Clearly, my arguments, even if they are sound, would not tilt the balance conclusively in favor of the tenseless theory of time. There may be other 
more plausible attempts to avoid McTaggart's paradox, and the tenseless theory is not without its difficulties. This essay should, however, bring one central issue of the debate sharper into focus. The tenseless theorist maintains that the tensed theory is dialectically inadequate, being unable to account for or ground the reality of time, understood in terms of temporal relations between and among events. The tensed theory insists that temporal passage must constitute the core of time because there are indisputable phenomena, such as our experience of time and temporal passage, that can only be accounted for by appealing to the NOW. If the tenseless view can account for our experience of time and change (and I believe it can $)^{5}$ then together with my critique of recent tensed theories of time, the weight of philosophical argument would tip the balance on the side of the tenseless theory. On the other hand, if the detenser cannot expound an adequate account of our experience of time, then the urgency to provide a consistent and illuminating version of the tensed theory will be all the more pressing. ${ }^{6.7}$

\section{NOTES}

${ }^{1}$ McTaggart's essay was originally published in (1908) and reprinted in (1934). All page references to this article will be from (1934). Cf McTaggart (1927).

${ }^{2}$ For Smith's most sustained defense of the tensed theory see (Smith 1993). Other recent tensed theories that attempt to deal with McTaggart's paradox are found in Schlesinger (1991), (1993) and(1994), Bigelow(1991), andZeilicovici (1989). Bigelow and Schlesinger both attempt to avoid the view that temporal becoming is contradictory by appealing to the notion of possible worlds. For criticisms of Bigelow's theory, many of which also apply to Schlesinger's, see Oaklander, (1994c). Zeilicovici proposes the idea that we can explain temporal becoming even if we reject the idea of the moving NOW as a property that moves along the series of events. I criticize Zeilicovici in Oaklander (1992). For a criticism of Prior-type theories of tensed time see Oaklander (1984) and Smith (1993).

McTaggart's paradox has been recently discussed in a debate between E. J. Lowe, Hugh Mellor and Robin Le Poidevin. Cf Le Poidevin and Mellor (1987a), Le Poidevin (1991, 1993), and Lowe (1987a, 1987b, 1992, 1993). Although Lowe argues against McTaggart's negative thesis, and claims to defend a tensed theory of time, his own account of the metaphysical significance of the tenses is too skeletal to be considered in this paper.

${ }^{3}$ In (1993, p. 171) Smith explicitly introduces earlier and later into his analysis of the tenses since he claims that the tensed theory implies "E is present, was future and will be past, or $\mathrm{E}$ is future, and was present and (still earlier) was past and $\mathrm{E}$ is future, will be present and will be (still later) past". However, if my argument of the past few pages is correct, then these B-terms cannot perform the function for which they were introduced, namely, to provide an ontological ground for an event having incompatible A-properties successively (in the past or in the future).

${ }^{4}$ Smith might reply to this argument by claiming that what distinguishes the two tensed facts (5) and (7) is that one contains the inherencez of futurity and the other contains the inherencez of pastness. What, then, is the ground of the temporal relation of E's being 
future before E's being past? He cannot say that it involves a temporal relation between the inherence 2 of futurity and the inherence 2 of pastness, since both inherence relations are present, and the B-relation of earlier than cannot obtain between items that are both present. Indeed, it seems to me that in Smith's ontology, there are no temporal relations at all because he maintains that only what is past, present or future exists (Smith 1993, p. $165)$, and he is committed to the view that temporal relations are not past, present or future. For, being earlier than is a first order relation and therefore, if it had any A-properties, then they would be second-order properties. But Smith says that A-properties are first-order properties. It follows that they cannot be exemplified by B-relations which, therefore, do not exist.

${ }^{5}$ For recent tenseless accounts of time and experience, as well as criticisms of those accounts, see (Oaklander and Smith 1994, Pt. III).

${ }^{6}$ Upon completing this paper I have come across another recent defense of the tensed theory of time (Markosian 1993). A consideration of Markosian's views will, however, have to wait for another occasion.

${ }^{7}$ I wish to thank Quentin Smith and an anonymous referee for Synthese for their very helpful comments on earlier versions of this paper.

\section{REFERENCES}

Bigelow, J.: 1991, 'Worlds Enough for Time', Nous 45, 1-20.

Broad, C. D.: 1921, 'Time', in J. Hastings (ed.), Encyclopedia of Philosophy, Rpt. in 1955, Charles Scribner Sons, New York, pp. 334-345.

Broad, C. D.: 1923, Scientific Thought, Routledge and Kegan Paul Ltd., London. Rpt. in 1959, Littlefield, Adams \& Co., Patterson, New Jersey.

Broad, C. D.: 1938, An Examination of McTaggart's Philosophy, vol. 2, pt. I. Cambridge University Press, Cambridge. Rpt. in 1976, Octagon Books, New York.

Buller, D. J. and T. A. Foster: 1992, 'The New Paradox of Temporal Transience', The Philosophical Quarterly 42, 257-266.

Gtiinbaum, A.: 1973, Philosophical Problems of Space and Time, 2nd edn. D. Reidel Publishing Co., Dordrecht.

Le Poidevin, R. and D. H. Mellor: 1987, 'Time, Change and the Indexical Fallacy', Mind 96,534-38.

Le Poidevin, R.: 1991, Time, Cause and Contradiction, Macmillan, Basingstoke.

Le Poidevin, R.: 1993, 'Lowe on McTaggart', Mind 102, 162-70.

Levison, A. B.: 1987, 'Events and Time's Flow', Mind96, 131-43.

Lowe, E. J.: 1987a, 'The Indexical Fallacy in McTaggart's Proof ofthe Unreality of Time', Mind 96, 62-70.

Lowe, E. J.: 1987b, 'Reply toLe Poidevin and Mellor', Mind 96, 539-42.

Lowe, E. J.: 1992, 'McTaggart's Paradox Revisited', Mind 101, 323-26.

Lowe, E. J.: 1993, 'Comment on Le Poidevin', Mind 102, 171-73.

Markosian, N.: 1993, 'How Fast Does Time Fly?', Philosophy and Phenomenological Research 53, 829-44.

McTaggart, J. E. M.: 1908, 'The Unreality of Time', Mind 18,457-74, and rpt. 1934, S. V. Keeling (ed.), Philosophical Studies, Edward \& Arnold \& Co., London, pp. 110-34. 
McTaggart, J. E. M.: 1927, 'Time', in C. D. Broad (ed.), The Nature of Existence, vol. II, Cambridge University Press, Cambridge. Rpt. 1968, Scholarly Press, Grosse Pointe, Michigan, pp. 9--31.

Mellor, D. H.: 1981, Real Time, Cambridge University Press. Cambridge.

Oaklander, L. N.: 1984, Temporal Relations and Temporal Becoming, Univ. Press of America, Lanham, MD.

Oaklander, L. N.: 1992, 'Zeilicovici on Temporal Becoming', Philosophia 21, 329--34. Rpt. in L. N. Oaklander and Q. Smith (1994a), pp. 252-256.

Oaklander, L. N. and Q. Smith (eds.): 1994a, The New Theory of Time, Yale University Press, New Haven.

Oaklander, L. N.: 1994b, 'McTaggart's Paradox and the Infinite Regress of Temporal Attributions: A Reply to Smith', in L. N. Oaklander and Q. Smith (1994a), pp. 195--201.

Oaklander, L. N.: 1994c, 'Bigelow, Possible Worlds and the Passage of Time', Analysis 54(4), 244--48.

Prior, A. N.: 1967, Past, Present and Future, Oxford University Press, Oxford.

Prior, A. N.: 1968, Papers on Time and Tense, Oxford University Press, Oxford.

Russell, B.: 1915, 'On the Experience ofTime', Monist, 25,212-33.

Schlesinger, G.: 1991, 'E Pur Si Mauve', The Philosophical Quarterly 41,427--41.

Schlesinger, G.: 1993, 'A Short Defence ofTempora1 Transience', The Philosophical Quarterly 43, 359--61.

Schlesinger, G.: 1994, 'The Stream of Time', in Timely Topics, The MacMillan Press, Ltd., London, pp. 63-94. Rpt. in L. N. Oak1ander and Q. Smith (1994a), pp. 257-285.

Shorter, J. M.: 1984, 'The Reality of Time', Philosophia 14,321-39.

Smith, Q.: 1993, Language and Time, Oxford University Press, New York.

Smith, Q.: 1994a, 'McTaggart's Paradox and the Infinite Regress ofTemporal Attributions', in L. N. Oaklander and Q. Smith (1994a), pp. 180-194.

Smith, Q.: 1994b, 'The Logical Structure ofthe Debate about McTaggart's Paradox', in L. N. Oaklander and Q. Smith (1994a), pp. 202-210.

Williams, C.: 1994, 'The Phenomenology ofB-Time', in L. N. Oaklander and Q. Smith (1994a), pp. 360-372.

Zeilicovici, D.: 1989, 'Temporal Becoming Minus the Moving Now', Nm1s 23, 505--24.

Department of Philosophy

University of Michigan-Flint

Flint, MI 48502-2186

U.S.A.

Made available with kind permission from Springer Science+Business Media: Synthese, McTaggart's Paradox and Smith's Tensed Theory of Time, 107,1996, 205-221, L. Nathan Oaklander. 